\title{
EDUCAÇÃO DE SENSIBILIDADE: A MAESTRIA DOS SABERES TRADICIONAIS
}

\author{
Elni Elisa Willms ${ }^{1}$ \\ https://orcid.org/0000-0002-4693-9027
}

RESUMO: O texto tem por objetivo apresentar algumas contribuições sobre educação de sensibilidade e como essa postura educativa se apresenta no brincar, na capoeira e na literatura. Trata-se de pesquisa teórica ancorada no campo da antropologia do imaginário, com autores como Gilbert Durand, Marcos Ferreira-Santos, Rogério de Almeida, Michel Maffesoli, Bruno Duborgel, George Gusdorf, entre outros. Discute-se o papel do professor como mestre iniciador da criança no mundo da cultura; o direito ao tempo de brincar livre; a capoeira como prática de educação ancestral - coletiva, circular, com movimento, canto e dança -, além do papel da literatura como convite para pensar sobre a criança que sofre, todos aspectos ou modulações de uma educação de sensibilidade. Conclui-se que o brincar, a literatura e a capoeira evidenciam dimensões de uma educação de sensibilidade que podem conduzir à construção da relação mestre-aprendiz, ou maestria, minimizando assim mecanismos autoritários e etnocêntricos das práticas educativas.

PALAVRAS-CHAVE: Educação de sensibilidade, maestria, brincar.

\section{EDUCATION OF SENSIBILITY: MASTERING TRADITIONAL KNOWLEDGE}

ABSTRACT: The main aim of the present paper is to provide some contributions on Education of Sensibility, pointing out by what means this educational approach occurs in free play, capoeira and literature. The research is theoretically anchored on the work of anthropology of imaginary authors such as Marcos Ferreira-Santos, Rogério de Almeida, Gilbert Durand, Michel Maffesoli, Bruno Duborgel, George Gusdorf, among others. This paper discusses the role of the teacher as a master who initiates a child in the world of culture, regarding his or her right to have free play time, to have capoeira as a traditional educational practice - colective, circular, with movement, chanting and dance, as well as pondering on the role of literature as an invitation to think about children who undergo all aspects or modulations of an education of sensibility. The work leads us to conclude that free play, literature and capoeira highlight dimensions of education of sensibility, which may help to develop a master-apprentice relationship, or mastery, minimizing authoritarian and ethnocentric relations from educational

${ }^{1}$ Doutorado em Educação-FE/USP. Professora do PPGEdu UFMT/Centro Universitário de Rondonópolis. Rondonópolis - Mato Grosso - Brasil. elnielisaw@gmail.com 
practices.

KEYWORDS: Education of sensibility, Mastery, Free play.

\section{EDUCACIÓN DE SENSIBILIDAD: LA MAESTRÍA DE SABERES TRADICIONALES}

RESUMEN: El texto tiene como objetivo presentar algunas contribuciones sobre la educación de sensibilidad y cómo esta postura educativa se presenta en el juego, la capoeira y en la literatura. Es una investigación teórica fundamentada en el campo de la antropología del imaginario con autores como Marcos Ferreira-Santos, Rogério de Almeida, Gilbert Durand, Michel Maffesoli, Bruno Duborgel, George Gusdorf, entre otros. Se discute el papel del profesor como maestro iniciador del niño en el mundo de la cultura; el derecho a tener tiempo para jugar libremente; la capoeira como práctica de la educación ancestral (colectiva, circular, con movimiento, canto y baile), además del papel de la literatura como una invitación para pensar en el niño que sufre todos los aspectos o modulaciones de una educación de sensibilidad. Se concluye que el juego, la literatura y la capoeira muestran las dimensiones de una educación de sensibilidad que puede conducir a la construcción de la relación maestroaprendiz, o maestría, minimizando así los mecanismos autoritarios y etnocéntricos de las prácticas educativas.

PALABRAS CLAVE: Educación de Sensibilidad, Maestría, Jugar.

\section{Introdução}

Mas um mestre não se torna um mestre porque outros esperam dele a verdade. Ser mestre não é essencialmente uma forma de relação com outrem, uma dignidade que acontece para alguns pela solicitação de um aluno ou de um público. Repetindo ainda uma vez: a maior parte dos professores não são mestres.

(GUSDORF, 2003, p. 104).

O texto é parte do relatório final de um projeto de pesquisa e traz a fundamentação teórica dos estudos realizados sobre o brincar na perspectiva da educação de sensibilidade de Marcos Ferreira-Santos e Rogério de Almeida (2011; 2012); além das contribuições de Gilbert Durand (1988; 1989), Duborgel (1992), Michel Maffesoli (1985, 2001, 2003, 2005), entre outros autores afeitos ao campo da antropologia do imaginário. Embora pudesse ter sido feita aqui outras escolhas epistemológicas, a antropologia do imaginário tem ancorado 
minhas pesquisas e atuação profissional desde meados dos anos 90 do século $X X$, como se fosse um "poço inesgotável onde balde nenhum desce sem que volte repleto de ouro e bondade" (NIETZSCHE, 2008a, p. 17). Simbolicamente o poço é um lugar profundo, mas a ele me dirijo e retiro apenas um pouco d'água, o suficiente para saciar a sede, pois escolhi alguns expoentes desse imenso campo paradigmático aberto a muitas possibilidades de interpretação, consciente de que deixei de citar muitas referências igualmente importantes. Assim, talvez, e por conta da gama de conteúdos que busquei tratar por meio de interconexões, alguns leitores sintam falta de aprofundamento. Contudo, trata-se exatamente de uma aposta na escolha (ALMEIDA, 2010), ou seja, deixo vir do fundo das aparências (MAFFESOLI, 1996) uma certa intensidade que permite perceber com sensibilidade e ao longe o horizonte percorrido em minha trajetória acadêmica. Fica, assim, um convite de leitura generosa para outras percepções a partir do que aqui narro e referencio.

Escolhi deixar reverberar ao longo do texto muitas epígrafes, ao modo do coro na tragédia grega (NIETZSCHE 2008; MAFFESOLI 2003; 2005). São vozes que anunciam ou sublinham uma ideia central para aquela seção. Trata-se de um certo estilo híbrido que me é próprio, uma certa embriaguez poética e dionisíaca, que, todavia, se faz ancorada no referencial teórico com um sentido quase apolíneo. O mensageiro Hermes ajuda-me a fazer o trânsito entre a sensibilidade e a razão. Na conclusão retomo esse aspecto.

Feitas essas ressalvas, abordo inicialmente o conceito de educação de sensibilidade. Em seguida, na segunda seção, lanço algumas bases teóricas em diálogo com descrições do brincar como experiência de imaginação e alteridade. Trata-se de um exercício que exige tomada de atitude: Como professores podem propor atividades, brincar e aprender com as crianças? É disso que trato na terceira seção do texto para, na quarta, apontar a literatura como um dos itinerários de formação para acessar a dimensão humana no processo de construção da maestria. É principalmente George Gusdorf - contudo os demais autores citados no texto convergem entre si - quem ancora a quinta seção do texto, para abordar a dimensão da maestria. Na sexta seção faço uma relação entre a atividade de capoeira como uma clara expressão de maestria e educação de sensibilidade que muito pode nos ensinar. E conclui-se que o brincar, a literatura e a capoeira evidenciam dimensões de uma educação de sensibilidade que podem conduzir o processo da relação mestre-aprendiz, ou maestria. 


\title{
Educação de sensibilidade
}

Ferreira-Santos \& Almeida (2012, p. 69) postulam a ideia de uma Educação de Sensibilidade a partir dos seguintes termos:

\begin{abstract}
Trata-se de uma modalidade possível de se compreender e agir no âmbito dos processos educativos, sejam eles em termos de autoformação, seja no modelo escolar, a partir de uma razão sensível, do exercício da imaginação, da experimentação poética e valorização do imaginário para lidar com a alteridade sem mecanismos etnocêntricos. Aqui se privilegia o refinamento da sensibilidade através de todos os sentidos (visão, audição, paladar, tato, olfato, intuição, cinestesia), com a preocupação de inter-relacionar ética e estética num contexto dialógico em que mestre e aprendiz troquem, incessantemente, de lugar, atualizando o arquétipo do mestre-aprendiz.
\end{abstract}

Nessa vertente, como apontam os autores, a educação é um processo ao longo da vida em que comparecem todos os sentidos experimentados pelo corpo. Dessa forma, alguns se educam fazendo algo com as mãos - farinha, tecido, mas também bordam, fiam, esculpem, forjam o ferro, manipulam as rochas, escrevem etc. Há os que ouvem, tocam ou cantam, há os que movimentam o corpo na dança e nos esportes, os que fotografam, filmam, narram estórias, enfim, é com o corpo que habitamos o mundo, produzindo cultura. A definição de educação apresentada por Beatriz Fétizon (2002, p. 178) aprofunda o que se está afirmando aqui:

\footnotetext{
Ora, se de um lado educação é vida e para a vida, e se viver é agir, e se agir é escolher, decidir, então a educação é o exercício da e a preparação para $a$ escolha, a decisão, a opção - o que requer a cultura (regime interno vital). Eis aí. E se, por outro lado, a posse da humanidade só se opera no universo da cultura (ou da história), a atividade educativa (formal ou informal) é o preciosíssimo instrumento que o grupo humano (e só ele - até onde se saiba...) possui para promover a autoconstrução da humanidade de seus membros e a da individualidade de seus homens (Grifos da autora).
}

Como exposto pela educadora, não se trata de adquirir habilidades instrumentais com finalidade técnica de apenas servir ao mercado de trabalho, mas de agir, escolher e experimentar o sentido mesmo da palavra educar em sua etimologia a partir da raiz latina exducere, ou seja, fazer vir para fora algo 
que está na pessoa como potência. Nesse sentido socrático, o professor, como mestre iniciador das gerações no âmbito da cultura, é uma espécie de parteira, ou seja, ele ajuda a trazer para fora o que já está na corporeidade da pessoa. E aqui adentro noutro sentido profundo desta palavra, tão cara a este campo teórico, que é a noção de pessoa:

Prósopon é o termo grego que mais se aproxima de pessoa: "aquele que afronta com sua presença" [...] mais próxima da pessoa como prósopon está a concepção teatral dionisíaca que extrai sentido da máscara como personnare (aquilo que ressoa como verbo e não como substantivo), em que a máscara é utilizada pelo ator [...] para ajudar a extrair e projetar a voz (o mais íntimo de si mesmo), pois a máscara aqui funcionaria como caixa de ressonância (FERREIRA-SANTOS \& ALMEIDA, 2012, p. 129).

É nesse sentido que ao longo do texto vamos explorar como esse conceito opera no cotidiano das crianças, dos mestres de capoeira e dos professores, ou seja, como pessoas, que afrontam concretamente o mundo e suas resistências materiais (o corpo, as matérias e elementos da natureza) e imateriais (o medo, a insegurança, a rejeição, o abandono, a alegria, o amor...). É no embate das forças com as quais se defronta que o indivíduo vai, aos poucos, conquistando uma certa compreensão muito íntima de si e do mundo que habita: vai se educando e se tornando pessoa. Muitas vezes se é convocado a explorar facetas obscuras e latentes em si ou no confronto com aqueles com os quais somos instados a conviver. Quando em presença de alguns mestres, essa travessia pode ser melhor conduzida, na forma de parceria e apoio nos momentos difíceis pelos quais todos passam. Muitas vezes, também, a leitura de um livro - a literatura - apresenta-se como se fosse um mestre silencioso.

A antropologia do imaginário baseada na obra do francês Gilbert Durand "leva em conta a alteridade e a diferença, a integração dos opostos, insurgindo-se contra todas as reduções totalitárias e unidimensionais" (TEIXEIRA \& ARAÚJO, 2011, p. 13). Por essa razão, Durand oferece inestimável contribuição para os estudos no campo da educação, e aponta que com o advento do cartesianismo "A imaginação, como, aliás, a sensação, é rejeitada [...] tal como a senhora do erro" (DURAND, 1988, p. 25), tornando, assim, apenas os aspectos materiais, concretos e mensuráveis, capazes de serem validados como ciência, notadamente a positivista.

Toda a teoria durandiana, então, é um esforço para mostrar a importância da imaginação, da percepção e da corporeidade na constituição do conhecimento, bem como do símbolo e do mito, para defender que "Todo 
simbolismo é, portanto, uma espécie de gnose" (DURAND, 1988, p. 35). O símbolo, para Durand, possui um caráter mediador entre o conhecimento concreto e experimental em sua dimensão criadora de sentidos e é ao mesmo tempo receptáculo concreto desse sentido. Tal como acontece, por exemplo, quando as pessoas brincam ou jogam capoeira, como se verá mais adiante neste texto. Para o autor, a compreensão simbólica seria "uma espécie de modelagem global, expressiva, viva" (DURAND, 1988, p. 59) de uma "presença inelutável do sentido que faz com que, para a consciência humana, nada seja simplesmente apresentado, mas tudo seja representado" (DURAND, 1988, p. 59, grifos do autor). A seguir faço uma leitura simbólica, ou hermenêutica, do brincar e da capoeira, na tentativa de reunir aspectos re-apresentados simbolicamente nos gestos, e que fazem jorrar potências de uma educação de sensibilidade.

Assim, afirma-se, com esta postura epistemológica, que os campos da arte - acessada brevemente aqui por meio da literatura - podem servir como iniciação (de um processo perene) das pessoas na criação de si mesmas, em relação com o mundo e com o outro. Compreende-se, nesse sentido, que a arte

[...] remete a um conjunto de elementos. Ela é "procura" e, consequentemente, "recusa da rotina". Ela sacode, através do humor e da ironia, os dados do "bom senso", os conformismos, os confortos da vida e do pensamento, e os preconceitos enraizados. Ela alimenta-se dos sonhos que se encontram sempre presentes. Ela joga com as palavras e com as imagens, mas num jogo duplo onde se diluem as fronteiras entre o real e o imaginário, o jogo e o drama, o bom senso e a "loucura", o sério e o não sério. Ela é experiência da beleza, ela é divertimento e felicidade, não se limitando a ser nem uma "simples proposta de prazer", nem uma "abordagem superficial da estética, nem ainda um lazer em vão". Os processos artísticos representam "pelo menos 70 por cento dos processos de inteligência" se não tivermos problemas em admitir que a inteligência não é de modo algum co-extensiva a alguns processos de atividade formal do espírito, mas que comporta igualmente os atos da intuição, da sensibilidade e da imaginação (DUBORGEL, 1992, p. 70, grifos do autor).

As crianças, quando brincam, parecem reapresentar essa recusa da rotina e conformismos ao fazer uso da imaginação, da intuição e de muita criatividade. Entretanto, no embate de forças em que a sociedade nos obriga a lutar de acordo com as regras do mercado de trabalho, o ócio, o jogo, o brincar, a imaginação e a arte costumam ser relegados a espaços menores, quase inexistentes, não só para o adulto como também para as crianças. Nes- 
ta sociedade que elege o capital como um deus, todo o nosso tempo precisa ser ocupado por algo que produza, que dê resultados práticos, concretos, objetivos e/ou econômicos. Ao invés de destinar tempo para o brincar livre, muitos pais ocupam as agendas de seus filhos com horas e aulas de inglês, judô, natação, balé etc., transformando as vidas das crianças numa maratona de compromissos. Igualmente para os adultos, nesta sociedade, os tempos para as atividades de lazer e de vivência estética não são valorizados. Muitas vezes é preciso negociar ou, talvez, fazer atividades que nos dão prazer à margem do estabelecido, do que esperam de nós e de nossos trabalhos, chegando a gerar uma luta interna dentro de nós mesmos, para que aceitemos o tempo livre como necessidade vital: quantas vezes violentamos nosso corpo com excesso de trabalho dia e noite, "esquecendo" que ele precisa de cuidados, de exercícios físicos regulares, de alimentação saudável e de descanso? É disso que se trata quando defendemos a necessidade vital de ter tempo para cuidar de si.

Essa reflexão aplica-se também ao tempo que às crianças é destinado para brincar livremente. Desde que entra na escola - espaço institucionalizado e de recolhimento, poucas vezes de educação sensível - a criança é submetida a rotinas em que o tempo comanda todo o processo, ela é posta numa rotina que busca disciplinar o seu tempo. Que tempo a criança tem para imaginar e brincar livremente? Maffesoli (2005, p. 27) defende que "precisamos compreender a improdutividade" (Grifo do autor) como uma necessidade da criança, no sentido de que estando livre possa fazer escolhas. E fazer escolhas nos remete aos exercícios vitais de autonomia e responsabilidade, como apontado por Beatriz Fétizon (2002). Não podemos nos render à imposição produtivista ou pedagógica - que a tudo quer controlar -, sobretudo quando se pensa no brincar de crianças pequenas. Ou seja, como apontou George Gusdorf (2003) na primeira epígrafe, a maior parte dos professores não são mestres, mas apenas pedagogos no sentido de que conduzem quase todas as atividades e controlam o tempo das crianças.

\section{O brincar como experiência de imaginação e alteridade}

A própria razão é plural, ela não pode de modo algum resumir-se num racionalismo causalista e unívoco. (MAFFESOLI, 2001, p. 72) A imaginação é um poder demiúrgico. Ela é aquilo através do qual o homem põe o mundo em representação, aí se insere e aí se sente "em casa". (DUBORGEL, 1992, p. 295. Grifos do autor)

A partir das contribuições da teoria do imaginário de Gilbert Durand 
(1989) compreende-se a importância das vivências corporais, portanto, sensoriais e mediadas pela imaginação, que a criança necessita para desenvolver-se por meio do brincar. Precisamos incorporar a carga semântica dessa compreensão do tempo livre para o brincar, no sentido de um "corpo que afronta, que acaricia, que fere, que ama" (MAFFESOLI, 2005, p. 27). Uma experiência de religação da pessoa, como a compreendemos aqui, seja ela criança ou adulto.

A palavra experiência, para Larrosa (2014), contempla vários sentidos, a partir de sua etimologia: ela implica as ideias de perigo e travessia; aquele que faz uma experiência se expõe a atravessar um espaço indeterminado, perigoso até, exatamente, porque não controla todas as variáveis nem todos os eventos que possam acontecer enquanto passa por ou se expõe a essa travessia, tal como um pirata, por exemplo, que corre riscos por andar à margem da lei, expondo-se ao mar e às suas ameaças, vulnerabilidades e perigos, afrontando e lutando pelo desejo de sair vitorioso. Porém, nem sempre o pirata logra êxito, assim como ocorre com quem tudo pretende controlar. Ainda para o autor, a experiência é o lugar de quem padece ou sofre algo, ou de alguém apaixonado, um sujeito que se submete a algo definido por sua vontade e que, por isso, sofre uma transformação. À paixão pode-se atribuir vários sentidos, mas o que nos interessa aqui é que a pessoa aceita ou assume o risco de algo que está fora dela, que ela não controla, mas que de alguma forma a submete:

\begin{abstract}
A paixão funda sobretudo uma liberdade dependente, determinada, vinculada, obrigada, inclusa, fundada não nela mesma, mas numa aceitação primeira de algo que está fora de mim, de algo que não sou eu e que por isso, justamente, é capaz de me apaixonar (LARROSA, 2014, p. 29).
\end{abstract}

Expor-se ao brincar livre com as crianças, numa espécie de mestiçagem de alteridades - mistura e troca incessante entre a imaginação das crianças e dos adultos por um determinado tempo e num certo espaço -, pressupõe certo perigo ou risco de não se controlar todo o processo. Mesmo assim, assume-se os riscos de se aprender algo novo, pois "somente o sujeito da experiência está, portanto, aberto à sua própria transformação" (LARROSA, 2014 , p. 28). Nesse contexto, adulto e criança assumem-se criativos, por se abrirem a algo inusitado, que pode acontecer ou não, que pode trazer algo novo ou não, que pode continuar ou não. Estamos tratando, portanto, da força da imaginação criadora, e segundo Gandhy Piorski:

As grandes imagens que nascem do imaginar, as sensações mais significativas vividas por uma criança em seu brincar, as impres- 
sões gravadas em sua memória e corpo provêm desse núcleo de forças, da imaginação criadora, ato capaz de acionar a energia vital. Não é qualquer imagem ou estímulo de experiência que gera na criança o estado criador. (2016, p. 60).

Esse autor aponta que não é pelo acesso a imagens externas das mídias de entretenimento, por exemplo, que se acionam essas imagens, mas pelo contato concreto e real com a matéria do mundo. É por isso que o brincar livre, alimentado pela imaginação demiúrgica de que trata Duborgel (1992) na epígrafe acima, apresenta-se como um campo de experiências plurais que enraíza a criança com a vida em seu sentido mais amplo e permite estar e se expandir no mundo, pelas tantas trocas que essa atividade propicia. Ao brincar, a criança exercita o poder da imaginação - de escolher, de decidir, de mudar objetos de funções e de lugar - mas é também potência que leva a criança a participar do mundo, revelando-se e desvelando sentidos de si. A potência de crianças que sobem em árvores, por exemplo, pode ser percebida em detalhamentos: braços, pernas, pulsos e mãos fazendo força para se manter, segurar o peso do próprio corpo e ao mesmo tempo ascender na superfície para, em seguida, usar a mesma força ao descer, escorregando, mas igualmente sustentando-se. Crianças que fazem isso demonstram coragem de se entregar a uma situação que é transgressora e desafiante, mas que elas permitem-se enfrentar, com seus corpos. Essas experiências potentes preparam para outras travessias na vida adulta, pois acumulam-se vestígios dessa coragem, na memória corporal. E há aquelas que brincam sossegadamente... Mas quem sabe a que mergulhos profundos se lançam, em suas imaginações? Compreende-se, portanto, que a imaginação

... não poderia ser uma qualquer faculdade psicológica secundária; ela não é nem um auxiliar mais ou menos suspeito da razão, nem insignificante lazer ou repouso estetizante do objetivo sujeito da lógica ou da razão experimental, nem um prefácio longínquo, comovente e "infantil" do pensamento positivo. Ela é a "rainha das faculdades", "faculdade fundamental", irredutível e eminente poder humano de retomar em conta o universo numa forma outra, de o representar e re-criar como totalidade e unidade, como espelho do homem, homem ampliado, testemunho do sentido, imagem complexa da dramática humana, metáfora generalizada dos deuses, melhores ou piores, que definem as coordenadas das nossas nostalgias e os emblemas da nossa "realidade". Ela é sinal distintivo do homem ou, por outras palavras, do próprio poder e da audácia em instituir a similitude 
através do qual as figuras do homem, do mundo e dos "deuses" se intercambiam (DUBORGEL, 1992, p. 289-290, grifos do autor).

Defendemos aqui, por essa via de compreensão cujas vertentes brotam da antropologia do imaginário, que é fundamental os educadores vislumbrarem as potências da imaginação presentes no ato de brincar, como Duborgel menciona acima. Crianças quando brincam afirmam a existência, toda vez que criam algo, elas unem o objetivo com o subjetivo, dialogam com o visível e com o invisível, num jogo em que o mundo se define por suas aberturas aos ímpetos da imaginação criadora que, por seu turno, cria uma rede de circulação de saberes que irrigam o corpo e, por conseguinte, a vida toda dessas crianças. Nessa experiência de brincar, o mundo deixa de ser algo pronto, acabado e opaco, para se tornar um cosmos pulsante, vivo e orgânico, criado e articulado pelos seus desejos, que ela domina, mesmo que por breves instantes, pois interfere numa ordem já dada. Brincar pressupõe um movimento de transformação e pede uma dose de paixão pelo que se faz, num jogo de abertura ao mundo do outro, é uma espécie de aventura que tem a ver com a paixão amorosa, uma certa errância que não está de acordo com o controle produtivo de ter que aprender algo, sabendo-se, entretanto, que sempre se aprende algo.

A criança apreende o mundo brincando e, dessa maneira, vive um outro tempo. Não é o tempo da rotina, do relógio ou do produtivismo, tampouco o tempo pedagógico, do ter que aprender algo, com objetivos e estratégias pré-definidas. Brincar expõe a criança a viver o tempo eterno, de uma entrega àquilo que é naturalmente vivido e que dá intensidade ao presente como algo orgânico e amoroso. Trata-se de um tempo poético e cíclico, como um instantâneo divino. Para nós, pedagogos, tem sido bastante difícil compreender esse tempo do brincar da criança, temos dificuldade em permitir que a criança experimente o gozo do quietismo existencial apresentado por Maffesoli (2005, p. 36):

Esse gozo do tempo que passa não é necessariamente verbalizado; ele é naturalmente vivido de uma maneira quase intencional; mas ele impregna fortemente uma poderosa sabedoria popular que, mesmo batizada, permanece necessariamente pagã. O mundo eterno não tem qualquer necessidade de esforço nem de qualquer fantasma produtivo, ele remete ao quietismo existencial.

Cada vez mais cedo colocamos as crianças em escolas e desejamos 
que aprendam algo em que está implícita, apenas, a imposição de tarefas e atividades ligadas à escrita e/ou ao racional. Queremos, como adultos, de todas as formas, oferecer algo para elas fazerem, limitando-as, muitas vezes, a atividades no papel, quando há um universo sensorial a ser explorado pelo corpo inteiro e pelo movimento da criança que, por sua vez, pede espaço. Das mais calmas às mais agitadas, elas têm o direito e a necessidade de escolher o que fazer, como fazer ou até não fazer nada e ficar observando, se isso lhes apetecer, pois observar também é uma forma de aprender. É preciso que nós, como pedagogos, compreendamos essa necessidade vital da criança de ter tempo para si, incluindo às suas possibilidades algum nível de decisão, o poder de escolher algo que elas desejam fazer. E, assim, como aponta Beatriz Fétizon (2002), elas se educam no confronto com o mundo e nas relações que mantém entre si.

Nessa espécie de movimento errante, perambulando, a criança vai perceber o que está à sua volta, como mundo que se apresenta a ela, e então poderá escolher o que fazer. Willms (2013) ao observar crianças entre oito meses e seis anos de idade, evidenciou a necessidade de que crianças precisam caminhar, subir e descer escadas, explorar o ambiente, sentar, olhar, observar, parar, escutar, entrar e sair dos diferentes espaços a que têm acesso, perguntar ou silenciar, até compreender o que elas desejam. Há aquelas que permanecem longo tempo paradas, quietas, escutando, observando: vivendo o seu tempo do seu jeito. $\mathrm{O}$ que pode fazer o adulto diante dessa diversidade de modos de existir? Ele pode manter-se atento, perceber, observar, respeitar e, se for o caso, oferecer escuta, responder, acolher, dirigir, cultivar-se disponível às indagações que possam vir dessas crianças. Tudo depende da sensibilidade desse adulto para perceber e compreender o que cada criança é. Há a necessidade de uma conexão sensível que não passa por ordenamentos apenas do que é racional. Talvez seja o caso de uma certa cumplicidade muito respeitosa com o ser criança.

Esses movimentos aparentemente banais das crianças em direção ao mundo precisam ser compreendidos pelo adulto como essenciais ao desenvolvimento delas. Observamos cotidianamente crianças muito calmas e concentradas ficarem por longo tempo colocando pedrinhas dentro de uma garrafa; outras fazendo bolinhos de areia numa mureta, por um tempo que para nós pode parecer longo - não é um tempo mensurável pelo cronômetro, é o tempo da vida daquela criança, que ela escolheu livremente para viver aquilo. Esse tempo é o tempo eterno a que se refere Maffesoli (2005). Essas crianças, ao serem observadas por Willms (2013) não foram interrompidas 
por palavras de ordem ou comandos adultos: "Vamos todos brincar de roda!", ou, "Vamos todos desenhar!" Não! Elas foram respeitadas no direito de ficar fazendo o que desejavam fazer. No tempo e no ritmo delas, agiram, fizeram escolhas. São nesses momentos que nós adultos temos a oportunidade de perceber a autonomia que as crianças bem pequenas exercitam com grande dignidade, educando-se, portanto.

Com isso, não queremos dizer que o adulto não possa oferecer atividades às crianças, mas que pode haver um equilíbrio em que se preserve a necessidade da criança ter tempo para si, para ter a experiência da autonomia de escolher o que ela deseja fazer.

\title{
Como o professor pode propor atividades, brincar e aprender com as crianças?
}

\begin{abstract}
Quando se fala em olhar, observar, escutar crianças, adentramos um universo muito delicado, muito íntimo, pelo qual, antes de mais nada, precisamos ter grande respeito e reverência. $\mathrm{O}$ universo das crianças é sagrado. $E$, nesse sentido, são necessárias muita delicadeza e a humildade de - verdadeiramente - nos curvarmos e pedir "licença para adentrar os espaços sagrados infantis". (FRIEDMANN, 2014, p. 39)
\end{abstract}

Imaginemos um espaço onde brincam cerca de 70 crianças entre as idades de oito meses e seis anos (WILLMS, 2013). Um quintal ampliado, com ladeiras, três casinhas, uma pistinha para andar de motoca, um campinho para brincadeiras grupais, um tanque de areia, calçadas, corredores, um salão, um galinheiro, enfim, um espaço apropriado para vivências. O professor pode colocar sobre uma mesa alguns utensílios apropriados para brincar com argila; outro professor oferece lápis de cor, giz de cera e papel sulfite; um terceiro professor prepara uma mesa com pincéis, papel, água e tinta guache; noutro tempo, outro professor expõe papeis, cola e tesoura sobre um tapete; numa roda, outro professor aconchega alguns alunos e começa a contar histórias, oferece livros de literatura; ele também pode começar a brincar de roda ou cantar, pode começar a tocar algum instrumento e assim sucessivamente. 0 que se quer sugerir com todas essas opções é que o professor da educação infantil pode ser aquele que organiza o espaço, expõe os materiais e espera que aquelas crianças que desejarem fazer aquela atividade se aproximem. Elas podem chegar e sair a qualquer momento, podem permanecer muito ou pouco tempo, podem transitar de uma para outra atividade oferecida pelos adultos. Seria difícil para os professores pensarem em algo assim, mais aberto, 
imaginativo e intuitivo, para acolher as crianças?

A proposta é a de que o professor corra o risco de se experimentar nessa outra posição, aparentemente quase sem controle, ao mesmo tempo em que espera que a(s) criança(s) entre $(\mathrm{m})$ naquela atividade que o professor ofereceu (recorte, leitura, música, pintura, contação de histórias, modelagem em argila, brincadeira de roda etc.). O professor entraria, então, em contato com o controle de si, de sua ansiedade, o controle da emoção e do medo de errar ou de não dar tudo certo; desenvolveria uma postura de abertura para o que move o desejo da criança, enquanto espera, e essa espera precisa ser elaborada pelo professor. Podemos assegurar que viver essa experiência não se dá de maneira rápida, nem é fácil. É preciso um tempo para o professor acreditar que pode fazer diferente, ele precisa de coragem para se expor ao risco de nenhuma criança aderir àquela proposta, precisa da colaboração de outros professores mais experientes que já fazem assim, para o apoiarem, com um simples olhar e um leve sorriso para confirmar que, sim, está indo bem.

É necessário cultivar uma certa sensibilidade amorosa de si, até em relação àquilo que nos impede de ir além. Permitir-se sentir o que pulsa em nós e na criança como desejo e possibilidade de encontro. Ou não! E o que fazer se nenhuma criança aderir à nossa proposta? Como lidar com o medo de que não venha nenhuma criança? Pode ser a maior agonia. Medo de errar, de sermos vistos pelos outros professores como alguém incapaz. Precisamos elaborar o medo, amá-lo e acolhê-lo até resolvermos correr o risco, mergulhar, saltar do trampolim, nos jogarmos no caminho, alçar voo, não importa a metáfora, qualquer uma delas nos ajuda a dizer dos sentimentos que podem nos visitar, enquanto pensamos e escrevemos sobre o medo vivido. E vencido o medo, a experiência pode acontecer, como relata Willms (2013, p. 150):

O nosso diálogo selava o encanto de brincar: "O que você está fazendo, Pedro?", perguntei ao ver que ele cortava em pedaços quadradinhos uma massa de argila que havia esticado com o rolo. Ele respondeu: "Tô fazendo carne picadinha...". "Posso fazer uma vasilha para você pôr a carne picadinha?" Ele apenas balançou a cabeça afirmativamente e me pus a modelar uma vasilha de barro para acolher aquela carne. Era uma metáfora de que eu me tornava receptiva àquelas crianças e seus aprendizados, ou eram elas que me recebiam com seus brincares? [...] Era realmente um ritual cerimonioso, simples e complexo de ser aprendiz pesquisadora, aprendiz professora, aprendiz humana, nesse trajeto entre as minhas intimações e as emanações desse meio educativo. 
No recorte acima temos a vivência de uma educação de sensibilidade que, por sua vez, ancora-se numa razão sensível, lembrando com Maffesoli (2001, p. 61) que "há uma pluralidade de razões, e que é da conjunção das mesmas que nasce esse "surreal" que é a existência" (Grifo do autor), entre aquilo que enfrentamos - o medo - e o que acontece quando uma criança nos acolhe e podemos, juntas, fazer uma experiência de maestria:

\begin{abstract}
Configura a experiência estética do estar-no-mundo e suas imagens e símbolos, na busca constante de constituir sentido à existência. Sendo uma existência tríplice: Ser - com o Outro - no Mundo, o humano necessita expressar sua pertença e seu estranhamento através de formas simbólicas, as quais nos ensina o mestre Ernst Cassirer, são o mytho, a religião, a linguagem, a história, a ciência, a arte. A produção artística é, exatamente, o meio pelo qual a criação é colocada como questão ontológica para o humano. A rigor, sem esta criação, não há construção humana, pois é preciso lembrar também que a humanidade em nós é, duramente, construída no desfile solene dos minutos cotidianos do mais insólito banal. A humanidade em nós não é um dado a priori. É uma construção, um afrontamento. Portanto, há uma função "lógica" na simbolização da experiência sensível. (FERREIRA-SANTOS, 2001, p. 05).
\end{abstract}

Essa necessidade de perceber a nossa pertença estética - só acessível, portanto, por meio dos nossos sentidos - a este mundo se dá pelo contato que mantemos com as narrativas míticas, com as experiências corporais ao brincar e na capoeira, com a literatura e a arte em suas diversas manifestações, como apontado no trecho acima. Assim, no âmbito da nossa atuação como professoras estamos, a todo momento, exercitando essa tríplice condição existencial: somos, com o outro, no mundo. Somos desafiados a afrontar o mundo, a nós mesmos e aos outros. Também as crianças, quando brincam, fazem esse exercício nos momentos de disputa de brinquedos, quando têm que conceder a vez para que outra criança dê uma volta na bicicleta, quando num jogo de futebol driblam ou passam a bola para o companheiro, quando no brincar de casinha fazem uma festa de aniversário e todos juntos comemoram, cantam e batem palmas diante de um bolo imaginário. Esse exercício de imaginação entre as pulsações da natureza com a cultura configura a tarefa educativa na dimensão da maestria.

A ideia central, que pretendemos enfatizar acima e que estamos a experimentar como professoras nas pesquisas sobre o brincar, é a valorização de 
práticas e saberes ancestrais de educação e formação da pessoa integralmente, e não apenas como serviçal do mercado de trabalho, mas como educação de sensibilidade. Busca-se, assim, o sentido de "Jornada Interpretativa" defendida por Marcos Ferreira-Santos (2008): "A pessoa como ponto de tensão na construção cotidiana de sua humanitas" (p.1. Grifo do autor). Ou seja, concomitantemente entro em ação no mundo e ele interpela-me para a construção de sentidos: Porque faço o que faço com as crianças? Qual minha concepção de criança e infância? Como professora, eu valido o brincar?

Esse itinerário pode ser lido como Trajeto Antropológico a partir de Gilbert Durand (1989, p. 29): “a incessante troca que existe ao nível do imaginário entre as pulsões subjetivas e assimiladoras e as intimações objetivas que emanam do meio cósmico social". Elni Elisa Willms (2013) trata como "Escrevivendo" e Fridriech Nietzsche $(2005 ; 2010)$ com a divisa sobre educação: "Torna-te o que tu és". Vejamos a seguir, ainda que brevemente, como a literatura pode contribuir para que construamos essa noção de educação de sensibilidade e de maestria.

\section{De mãos dadas com a literatura, para acessar a dimensão da vida}

[A literatura] longe de ser um simples entretenimento, uma distração reservada às pessoas educadas, ela permite que cada um responda melhor à sua vocação de ser humano. (TODOROV, 2014, p. 24)

Na interface de alguns trabalhos sobre o brincar é possível dar as mãos à literatura (WILLMS, 2007; 2011; 2013; 2013b, 2015) para estabelecer relações com a arte, a educação e a cultura, sempre na perspectiva da formação humana, como aponta Todorov (2014, p. 22): "a literatura não nasce no vazio, mas no centro de um conjunto de discursos vivos, compartilhando com ele numerosas características". Alberto Filipe Araújo e Rogério de Almeida, apoiados nas concepções de Gilbert Durand, defendem que "Há uma ligação profunda entre mito, símbolo e vida, que se encontra na literatura" (ARAÚJO e ALMEIDA, 2018, p. 24). Dessa forma, aquele que lê entra em contato com os grandes temas da humanidade, entre eles a dor, a morte, o amor, o abandono, a rejeição, enfim, a imensa tapeçaria daquilo que se nos apresenta como Vida.

Roland Barthes (2013) aponta para este aspecto pungente que é o registro escrito, e que nos chega como literatura: "Entendo por literatura não um corpo ou uma sequência de obras, nem mesmo um setor de comércio 
ou de ensino, mas o grafo complexo das pegadas de uma prática: a prática de escrever" (p. 15, grifos do autor). Assim como os nossos antepassados, e ainda hoje muitos povos originários, usaram e usam a palavra oral para dizer de suas experiências de estar no mundo, hoje dispomos da literatura para grafar, registrar ou inscrever nosso modo de ser e de estar no mundo. Há outras formas, por certo, de expressar esse sentimento de estar vivo, como a dança, as artes plásticas, o teatro, o cinema, entretanto, aqui a literatura é o nosso foco, como defende Barthes:

\begin{abstract}
Se, por não sei que excesso de socialismo ou de barbárie, todas as nossas disciplinas devessem ser expulsas do ensino, exceto uma, é a disciplina literária que devia ser salva, pois todas as ciências estão presentes no monumento literário. É neste sentido que se pode dizer que a literatura, quaisquer que sejam as escolas em nome das quais ela se declara, é absolutamente, categoricamente realista: ela é a realidade, isto é, o próprio fulgor do real [...] A ciência é grosseira, a vida é sutil, e é para corrigir essa distância que a literatura nos importa. Por outro lado, o saber que ela mobiliza nunca é inteiro nem derradeiro; a literatura não diz que sabe alguma coisa, mas que sabe de alguma coisa; ou melhor, que ela sabe algo das coisas - que sabe muito sobre os homens (2013, p.18 e 19).
\end{abstract}

É essa riqueza de saberes, ultrapassando barreiras espaciais e temporais, que a literatura faz emergir e pode se constituir como um itinerário de formação, iniciação e maestria. Ao mobilizar as potências míticas e imaginárias de que se constituem as estórias, a literatura permite o encontro e o diálogo com questões profundas que nos afetam como pessoas. Quantos de nós teve nalguns autores os seus melhores mestres iniciadores? Quanto legado absorvemos quando, por exemplo, lemos Gibran Khalil Gibran (1977; 1980; 1981), Richard Bach (1977) ou Rainer Maria Rilke (1995) na juventude ou em qualquer etapa da vida? Por que a literatura não quer ensinar nada, mas como aponta Barthes, por "saber algo das coisas" ela se oferece como uma estória, e assim, e apenas por exemplo, ao entrar em contato com Fernão Capelo Gaivota (BACH, 1977), com as vicissitudes dessa ave, metaforicamente, pode-se aprender sobre o que é ser rejeitado por um bando e ter que iniciar outro caminho de maneira autônoma.

Citei apenas três autores acima aos quais tive acesso na juventude por uma espécie de oferta do acaso, posto que eu não contava com biblioteca no seio familiar ou escolar. Foi na casa de uma amiga de minha mãe que vi esses 
livros numa prateleira e por eles manifestei interesse de ler. Emprestados, eu os li com voracidade. Eles chegaram até a menina que morava no interior do Mato Grosso do Sul, em 1979, na hora certa. Com dezesseis anos de idade tive acesso à força e à ternura das compreensões filosófica, antropológica e poética que Gibran vertia em seus escritos, porém, foi somente no doutorado, em 2011, que meu orientador informou-me que Gibran era um leitor de Friedrich Nietzsche, entre muitos outros filósofos orientais e ocidentais. Posso afirmar que Gibran continua desempenhando sua maestria de maneira silenciosa, juntando-se mais tarde a João Guimarães Rosa, Clarice Lispector, Fernando Pessoa, entre outros. Esse meu exemplo soma-se a outros que conheço e que fizeram itinerários de formação quase sempre fora da escola, mas ao lado dos quadrinhos (BRÉSIO, 2016), dos contos de fadas (RUBIRA, 2006; 2015), dos filmes (ALMEIDA e FERREIRA-SANTOS, 2011; 2014), todos de alguma forma bebendo da maestria desse campo das artes sob a forma da literatura.

Então, para nos aproximarmos do humano que habita o professor e as crianças, pode-se buscar o suporte e o apoio nas obras literárias como meio de compreender o que se passa, por exemplo, com uma criança que sofre, como tantas que recebemos cotidianamente em nossas escolas. Mario de Andrade aborda em dois contos o tema humano do sofrimento da criança. Tanto em Piá não sofre? Sofre. (1992), como em Tempo da camisolinha (1999) narra-se o abandono e a opressão da criança. No conto Piá não sofre? Sofre o autor apresenta-nos a história de Paulino, filho de Teresinha, mulher cujo marido é preso. Teresinha e os dois filhos ficam morando com a mãe num barraco e em absoluta miséria.

Podia-se chamar de casa aquilo! Era um rancho de tropeiro onde ninguém não mora, de tão sujo. Dois aspetos de cadeira, a mesa e a cama. No assoalho havia mais um colchão, morado pelas baratas que de noite dançavam na cara da velha, o torê natural dos bichinhos desta vida" (ANDRADE, 1992, p. 85).

O filho mais velho, "felizardo", logo morre de tifo, porém, Paulino sobrevive em meio às desgraças de uma mãe desempregada, experimenta a violência, o abandono e a fome, chegando a comer formiga e terra, indícios de sua subnutrição. Um dia, sem mais nem menos, ele é retirado dos braços da mãe pela avó paterna que o leva para sua casa, como troféu na disputa entre sogra e nora. Longe de ser bem tratado, na casa da avó paterna é entregue aos cuidados de tias que o aterrorizam e o abandonam: 
[Paulino] "Quis se chegar pras moças porém elas tinham raiva dele, e podendo, beliscavam. [...] Acabava sempre aquilo, a menina com raiva bruta, vestindo depressa a camisolinha nele, machucando, "fica direito, peste!" pronto: um beliscão que doía tanto, meu Deus!" (ANDRADE, 1992, p. 93).

E assim, ao longo do conto, choca-nos como uma criança se torna desamparada e morre, por absoluta falta de sensibilidade para com essa vida. Quantas crianças em nossas escolas, ainda hoje, vivem situações semelhantes? Mães e pais alcoólatras, dependentes químicos, desempregados, vítimas da miséria social produzida por um sistema econômico cruel que usa e descarta as pessoas, as crianças, muitas vezes, sofrem as consequências de ações geopolíticas que as atingem diretamente, sob a forma de abandono. Falta moradia decente, falta comida à mesa, falta a dignidade de uma cama bem arrumada ou um copo de chá e um pedaço de pão antes de sair para a escola. Como aprender (e brincar) diante de tanto desamparo?

\title{
O aprendizado da maestria
}

\begin{abstract}
Trata-se de uma contribuição ao processo de reencantamento do mundo com um processo de iniciação mítica, onde o engendramento de Mestres (no sentido de Gusdorf) se dá na retomada do caminho mítico para a mestria. Não assunção do caminho do mestre, mas percepção e apropriação de seu próprio caminho para a mestria. [...] Não está no currículo escolar, mas na presença humana de um(a) iniciador(a) da Cultura. O programa é pretexto para o encontro. Silencioso encontro de diálogos abissais. (FERREIRA-SANTOS, 2004, p. 42)
\end{abstract}

O que pode o professor diante do abandono, desamparo e violência - social e pessoal - senão afirmar a vida? Acolher, no tempo e no espaço em que está com a criança, sendo um educador sensível, alguém que está ali para apresentar a vida, um mestre como aponta Gusdorf (2003), como aquele que se compromete com o significado permanente da condição humana em toda sua pluralidade. Nesse sentido, é digno de nota o papel de mestre que 
desempenha a professora Carmela no filme Numa escola de Havana (2014) ${ }^{2}$. Para Gusdorf (2003), poucos professores são mestres, além de tudo, não se faz mestre por decreto ou por colação de grau: trata-se de um longo caminho da conquista e conhecimento de si, muitas vezes em solidão, nesse trabalho quase alquímico de fazer nascer o que há de melhor como humano na forma de compreensão, afeto, disponibilidade e sensibilidade para acolher e escutar, sem julgar, essa outra vida que se apresenta diante de nós. Mestre é aquele que trabalha cotidianamente para que aspectos desviantes de sua personalidade se aprimorem no sentido de tornar-se parteiro de si mesmo, fazendo vir à luz o que de melhor palpita em si, para, posteriormente, fazer nascer o melhor do outro. Somente quando faz esse caminho, normalmente acompanhado por outro mestre, é que ele se torna apto à maestria junto de outros, e assim "pela graça do encontro, uma vida foi mudada" (GUSDORF, 2003 , p. 10). Lembramos que o encontro com um mestre pode se dar sob a forma de uma pessoa ou a obra de um escritor ou de vários escritores na forma de livros e filmes, como vimos apontando acima. É nesse sentido que "A presença real de Schopenhauer não foi dada a Nietzsche; o mestre só agiu sobre o discípulo pela ressonância de seus escritos" (GUSDORF, 2003, p. 156), e ainda o mesmo autor nos mostra como Sócrates agia:

Mestre da ironia, Sócrates questiona, refuta, argumenta, faz o interlocutor cair em contradições, mas não fornece à perturbação que provoca uma solução pré-fabricada. Desvenda enigmas, jamais dá a palavra do enigma. Nada permite esclarecer melhor o enigma do ensino. Sócrates não defende a sua própria causa, pela simples razão de que a verdade nunca pode ser um presente dado por um homem a outro homem. Ela é fruto de uma investigação e de uma conquista de cada um (GUSDORF, 2003, p. 11 e 12).

Portanto, mais do que dar respostas, um mestre nos devolve a nós mesmos, nesse exercício infindável de tornar-se quem se é, tomando a expressão tão cara a Nietzsche (2005). Entender o sentido profundo da maestria é

\footnotetext{
${ }^{2}$ Chala (Armando Valdes Freire), um garoto de onze anos, vive com sua mãe viciada em drogas, Sonia (Yuliet Cruz). Para sustentar a casa, ele treina cães de briga, indiretamente ajudado por um homem que pode ser ou não seu pai biológico. As dificuldades de sua vida refletem na escola, onde é aluno de Carmela (Alina Rodriguez), por quem ele tem um grande respeito. Mas quando ela fica doente e tem que se afastar, Chala não se adapta à nova professora, que sugere que ele seja transferido para um internato. Quando Carmela retorna, não aceita essa medida e outras imposições que aconteceram durante sua ausência. Enquanto a relação entre professora e aluno se intensifica, os dois passam a ser perseguidos na escola, levando a um conflito que reflete o complexo sistema contemporâneo de Cuba. (NUMA ESCOLA DE HAVANA, 2014)
} 
uma das exigências para uma educação de sensibilidade, afirmada desde o início, pois em convergência com o que vimos defendendo ao longo deste texto, a relação mestre-aprendiz, nas palavras de Steiner (2005, p. 12), implica em três cenários:

Há os Mestres que destroem seus discípulos psicologicamente e, em casos mais raros, fisicamente também. Subjugam seus espíritos, acabam com suas esperanças, aproveitam-se de sua dependência e de sua individualidade. O território da alma tem também seus vampiros. Em contrapartida, há os discípulos, pupilos e aprendizes que derrubam, traem e arruínam seus Mestres. (...) A terceira categoria é a da troca, a de um Eros de confiança recíproca e, de fato, de amor ("o discípulo amoroso" da Última Ceia). Por um processo de interação, de osmose, o Mestre aprende com seu discípulo enquanto lhe ensina. A intensidade do diálogo gera a amizade em seu mais elevado sentido (Grifos do autor).

É dessa relação amorosa que se alimenta a Filosofia em busca pelo conhecimento. O mestre, como uma pessoa que ama o ato de conhecer, contamina o aprendiz com este amor e, então, nesse encontro e em relação dialógica e respeitosa, constroem-se saberes e conhecimentos: de si, do mundo, e com o outro. É disso que trata a relação de maestria, uma autoridade que se constrói de maneira vital, como aponta Steiner (2005, p. 26): "Ensinar seriamente é pôr as mãos no que há de mais vital no ser humano. É tentar ter acesso ao que há de mais sensível e de mais íntimo da integridade de uma criança ou de um adulto".

Não se trata de relação de subordinação, mas de confiança, pelo exercício de uma humildade forjada na escuta e no olhar sensível, e ao mesmo tempo exigente para com o nosso aprendiz. Diante de um mestre sentimos que devemos prestar atenção e respeito, não porque ele nos pede, mas porque o testemunho de sua existência aparece diante de nós, há uma espécie de dignidade que sobressai em todos os seus gestos e atitudes: "A força do mestre é uma responsabilidade assumida. Primeiramente, responsabilidade assumida para com os outros, pois o mestre descobre que ele tem responsabilidade de alma" (GUSDORF, 2003, p. 104). Todas as vezes que observei alguns mestres de capoeira, pude perceber esses aspectos aqui levantados: eles manifestavam-se como mestres na forma de ser e agir, por meio dos valores forjados numa mistura equilibrada de serem exigentes e ao mesmo tempo compreensivos, razão e sensibilidade na medida certa do que tratamos aqui como educação 
de sensibilidade. Dessa forma, como mestres, iniciam seus aprendizes na arte em que eles também foram forjados, por sua vez, com outros mestres. Vai se constituindo, assim, uma rede de saberes feitos na experiência partilhada, com fortes fundamentos ancestrais, quase sempre, de valores comunitários e solidários. Como professores, nas escolas, poderíamos beber dessas fontes para somar aos nossos tantos saberes pedagógicos.

Gusdorf nos lembra, entretanto, que nem todo professor é mestre, mas que na humanidade muitos assim se fizeram e deixaram pistas, e com eles podemos aprender:

Uma lenta iniciação, marcada por ritos de passagem cada vez mais temíveis, fez de Michelangelo um mestre, como de Bach ou Mozart, de Mallarmé, de Rilke ou de Descartes. Cada um daqueles cujo exemplo se impõem aos homens teve antes de aprender, mas por caminhos que nada têm a ver com a progressão regular dos itinerários da escola, do aprendizado ou da universidade [...] Somente aquele que tudo obteve de si mesmo poderá exigir muito dos outros. O obstáculo entre cada um e si mesmo, essa resistência e essa recusa, essa incessante fuga de uma natureza sempre rebelde à perfeição (GUSDORF, 2003, p. 105 e 106).

Tal como afirmei acima quando fiz referências aos mestres iniciadores a que tive acesso por meio da literatura, há muitos outros mestres que as pessoas podem encontrar em suas trajetórias. Muitas vezes são pessoas muito simples, mas que, com a potência de suas presenças e saberes ancestrais, mantém viva a cultura popular brasileira por meio de grupos de bumba-meu-boi (SAURA, 2008) ou de tecelãs do interior de Minas Gerais (LEMOS, 2020). O que têm em comum esses dois exemplos? São pessoas que construíram em vida uma série de saberes, fruto da experiência legada pelos seus ancestrais, experiências às quais elas também se submeteram e assim se tornam aptas a iniciar outros membros da comunidade. Ensinam o que aprenderam, fazendo o que sabem fazer. Esses saberes se fazem pela observação, pelo fazer, pela experimentação, no jogo, na roda e na dança, cantando também, cotidianamente, dia e noite, com os elementos que estão próximos a cada comunidade. Quando nos aproximamos das trajetórias dessas pessoas, percebemos os caminhos mitológicos desses mestres iniciadores: silenciosos, fazem o seu trabalho. Quando o aprendiz está pronto, começa a ouvir, a ver, pede licença e então inicia-se. Pelas mãos e gestos do mestre iniciador o aprendiz se torna o que ele é. Como aponta Nietzsche, é preciso amar o seu destino: 
Admitindo-se que a tarefa, a destinação, o destino da tarefa que ultrapasse em muito a medida ordinária, nenhum perigo haveria maior do que perceber-se com essa tarefa. Que alguém se torne o que é pressupõe que não suspeite sequer remotamente o que é" (NIETZSCHE, 2008a, p. 45, grifos do autor).

Não saber exatamente que é mestre torna a pessoa aprendiz, aberta para buscar. E porque está constantemente a aprender, move-se. O autor toma partido de uma ideia igualmente potente: é preciso "amor de si, cultivo de si" (NIETZSCHE, 2008a, p. 46,) o que implica em aceitar o jogo da vida tal como ele se apresenta, com toda a sua carga trágica de acontecimentos absurdos e grandiosos. Amar a vida é a expressão máxima desse amor fati:

Minha fórmula para a grandeza no homem é amor fati: nada querer diferente, seja para trás, seja para a frente, seja em toda a eternidade. Não apenas suportar o necessário, menos ainda ocultá-lo - todo idealismo é mendacidade ante o necessário mas amá-lo (NIETZSCHE, 2008a, p. 49).

Amar a vida! Que insígnia grandiosa e desafiante, ao mesmo tempo. Como o próprio autor acima anuncia, o caminho da maestria às vezes é trilhado sob fortes angústias, impaciência e dúvidas: o mestre não está satisfeito e é justamente essa insatisfação que o move ao constante aprimoramento de si. Ele quer e sabe que pode mais, é exigente e, assim, vai avançando rumo à conquista cada vez maior de sua singularidade. Trata-se, muitas vezes, de um exercício solitário e de humildade, de lutas cotidianas contra o tédio, a preguiça, o medo e a imperfeição, mas que, caso haja persistência, a obra de uma vida ali se faz afirmativamente.

No filme mencionado anteriormente, percebemos o envolvimento de Carmela para com seu rebelde aluno Chala: ela o procurava quando ele estava em dificuldades, o escutava, pedia que prestasse pequenos serviços, mas também o orientava, aconselhava, era exigente e amorosa, ao mesmo tempo. Exemplifica-se a justa medida de uma razão sensível, fundamento de uma educação de sensibilidade. Mas há ainda muitas outras experiências de construção da maestria.

\section{A capoeira como um exemplo de maestria e educação de sensibilidade}

Aguçando a sensibilidade de nossos alunos numa clara tentativa de elisão dos etnocentrismos, onde a diferença e a alteridade 
sejam valores solidários, minimizando o preconceito e a intolerância, esta educação de sensibilidade, numa prática crepuscular, no sentido que vimos tratando, circularia imagens-lembranças sob o pretexto dos conteúdos programáticos do currículo escolar. Tal prática desemboca na iniciação à humanidade no humano e na constituição e engendramento de mestres, no sentido preciso de Gusdorf. Para tanto, uma abertura inicial é imprescindível. $\mathrm{Na}$ nova atitude e mentalidade percebemos algo tão antigo como arquetipal: a paixão pelo Outro, abertura na presença humana, numa palavra: respeito. (FERREIRA-SANTOS, 2001, p. 05).

Assim agem os mestres nas rodas de capoeira, afinados com a epígrafe acima, iniciando gerações de pessoas por meio de uma manifestação cultural brasileira reconhecida por sua riqueza musical e gestual, o que a aproxima também de uma espécie de dança, que lembra jogos de combate de sociedades tradicionais:

A roda de capoeira, nesse sentido, é a forma de expressão que permitiu o aprendizado e a expansão do jogo. Nela se encenam golpes e movimentos acrobáticos, cânticos antigos são reatualizados e outros são inventados, acompanhados por uma orquestra de instrumentos que produz uma sonoridade múltipla e, ao mesmo tempo, característica da arte. A roda é um momento determinante da prática da capoeira que não pode ser ignorado. Seja na Capoeira Angola, Regional ou a que funde as duas vertentes, a roda é um espaço de criação artística e de performance cultural em que se realiza plenamente a multidimensionalidade da capoeira. Portanto, a roda também precisa ser registrada, assim como os mestres, depositários do saber imaterial da capoeira (IPHAN, 2008, p. 118).

A legitimidade dos saberes de um mestre de capoeira é construída ao longo de muito tempo de preparo, como se fosse uma árvore que, desde suas raízes mais profundas faz vir à copa os frutos para continuar sua espécie. Em geral são reconhecidos como pessoas acolhedoras, sensíveis e fortes, ao mesmo tempo alegres e exigentes, sabem como construir relações respeitosas, sabem como exigir para que seus aprendizes tenham disciplina, executem os movimentos rumo a uma perfeição lenta, porém, contínua. Costumam ser calmos, têm uma postura corporal digna e de autoconfiança, sabem respeitar, ao mesmo tempo que exigem os limites e os ritmos apropriados a cada um dos alunos.

Outro ensinamento forte dos mestres é o aprendizado em roda, no 
coletivo. Os mestres ensinam entrando na roda, jogando do seu jeito, mas também ensinam na medida em que permitem a observação de todos, pois uma vez que se entra na roda a pessoa faz a sua apresentação para os demais e assim todos têm oportunidade de aprender. Há, dessa forma, uma circularidade de saberes corporais experimentados na comunhão de cantos, movimento, ritmo, força, habilidade, ginga, astúcia para desviar-se, recuar, abaixar, erguerse, enfim, uma série de aprendizagens que, brincando corporalmente, ensinam atitudes diante da vida. Normalmente os movimentos da capoeira atingem três dimensões: alguns rente ao chão, outros ao nível da cintura, chegando até aos movimentos mais amplos e altos. O mestre proporciona esses aprendizados por meio da experiência corporal. Não é verborragia sobre o tema, trata-se de vivência corporal e comunitária, uma construção social e humana. Eles são considerados como Mestres da Cultura Popular (PAIVA, 2007), pois ensinam por meio de práticas manuais, corporais e espirituais, ou seja, por meio do exemplo. Por deterem conhecimentos comprovados sobre o que ensinam, são referências nos lugares onde vivem e atuam. Por suas ações e interações, acabam sendo reconhecidos, legitimados e valorizados.

Há também outra dimensão no trabalho com capoeira que podemos aprender com os mestres dessa arte: eles ensinam cantando. Cada canto de capoeira é como se fosse uma pequena semente de sabedoria popular. Os cantos populares são gotas de sabedoria que nos inundam de algo que, por vezes, na hora que os recitamos, ouvimos ou recebemos, não nos damos conta que ali um mensageiro deixa seu recado: "Eu não sou daqui, marinheiro só..."; "Sai, sai, sai! Ó piaba saia da lagoa!”; "Eh coroa santa. Abra esta porta pra felicidade entrar"; "Onde está a margarida, olê, olê, olá / Ela está em seu castelo / tira uma pedra, outra pedra... / e apareceu a margarida, olê, olê, olá."

Percebe-se o que se está cantando? Ter que sair do castelo, tirar as pedras para que a flor desabroche, trata-se, portanto, de cantos iniciáticos, canta-se como se deve fazer para se ter acesso ao centro de si... A maioria das pessoas ouve e não escuta. Mas um dia, de repente, o sentido aflora: o que tem a ver a piaba sair da lagoa, afinal? Simbolicamente podemos dizer que é preciso sair do lugar restrito ou conhecido para deixar a felicidade entrar, fazer um outro caminho ou novas experiências, quem sabe. Ou que é preciso tirar uma pedra de vergonha, outra do medo, outra da incerteza ou da angústia para que apareça a margarida, simbolizada por uma flor ou realização de si. Rítmica e repetidamente, esses cantos vão sendo entoados e então chega um momento em que a escuta faz sentido e o canto passa a ter poder: ele afirma o caminho da iniciação. Como se aquele ou aqueles que cantam estivessem 
preparando o terreno, aos poucos e com a suavidade de uma canção para uma revelação que ainda virá.

Gilbert Durand (1989) cita uma passagem de Phantsien über die Kunst, de Tieck e traduz as vivências com os cantos que aqui expressamos e que se pode observar nas vivências de capoeira:

A música opera o milagre de tocar em nós o núcleo mais secreto, o ponto de enraizamento de todas as recordações e de fazer dele por um instante o centro do mundo feérico, comparável a sementes enfeitiçadas, os sons ganham raízes em nós com uma rapidez mágica... num abrir e fechar de olhos sentimos o murmúrio de um bosque semeado de flores maravilhosas (p. 155).

A simples leitura desse trecho que fala da música quase nos transporta ao mundo das fadas pelas imagens que evoca. Então, assim como que encantados também numa roda de capoeira, quem sabe o professor possa iniciar-se, pelo movimento corporal e com música, uma trajetória de maestria.

\section{Considerações infindas...}

Entendida desta forma, a educação de sensibilidade perpassa as práticas iniciáticas à Cultura (mundo simbólico), através da cultura (no sentido agrário e hermesiano) das várias culturas (de grupos sociais num determinado espaço-tempo). Valendo-se das Artes (plásticas, musicais, literárias, videográficas e fílmicas) em que as imagens e os símbolos, articulados em narrativas articulam, por sua vez, o patrimônio histórico-cultural do humano e sua memória com o repertório cultural cotidiano dos alunos e suas trajetórias individuais, tornando-os significativos, e possibilitando-Ihes a sua apropriação, perlaboração e re-elaboração poética. O conhecimento retorna, então, ao coração, cumprindo seu destino. (FERREIRA-SANTOS, 2001, p. 05, grifos do autor)

Iniciei este texto convocando as figuras míticas de Dionísio, Apolo e Hermes, pois para aqueles que trabalham com a antropologia do imaginário, esse cenário mitológico é essencial para adentrarmos camadas de compreensão. Dionísio é tido como o deus festeiro, da embriaguez, da transgressão, e é ele que me sustenta quando ouso trazer três áreas - a literatura, o brincar e a capoeira que em si pediriam, cada uma, uma biblioteca. Trago também as epígrafes, quase excessivas, mas com o profundo sentimento de que essa parte do texto possa ser lida e considerada como parte do todo. Nenhuma escolha 
de autor foi arbitrária, tão pouco a ausência daqueles que, embora os conheça, não os citei. Há limites até mesmo para quem é dionisíaco.

Apolo é considerado por muitos como o deus da modernidade, aquele que clareia, ilumina, dirige o pensamento, governa a razão, impulsiona toda sorte de progresso material e econômico. Como sociedade e civilização sabemos bem os efeitos positivos - um certo conforto material, amplitude de comunicações etc. - e os efeitos perversos desse excesso de controle e subjugação da natureza a que esse impulso nos tem conduzido. Finalizo este texto em plena pandemia da Covid-19, ocasionada pela crise de emergência climática (SATO, 2020).

Ao descrever o que é um mestre de capoeira, volto o olhar para o professor como mestre e então percebo o quanto nos distanciamos da maestria nas escolas. No entanto, busco afirmar, por alguns exemplos próprios e também de outros autores, essa dimensão da maestria dos saberes tradicionais aqui abordados pela via do brincar e da literatura. Há outros itinerários possíveis, porém, no âmbito deste texto, tentei interpretar algumas dimensões dessas três possibilidades.

Os mestres de capoeira, partilhando saberes ancestrais cujas raízes mais profundas estão no continente africano, contribuem para a formação humana das crianças, adolescentes, jovens e adultos que se iniciam na roda, por meio do exercício corporal e dos cantos. O mestre tem um conhecimento comunitário a transmitir porque o experimentou como forma de vida e tem sabedoria para fazê-lo. Ele passou pelo caminho, fez a travessia, percorreu o itinerário todo, portanto, está apto a iniciar novas gerações.

A literatura - uma pequena menção a um filme é apenas um aperitivo que se conjuga à literatura para realçar aspectos que pretendi tratar - abordada aqui sob uma perspectiva estética, ou seja, pelos sentidos, se oferece para pensar algo da realidade, ao trazer dimensões do humano, possibilita experimentar sentimentos de ternura e compreensão às tantas formas de que se reveste a existência. Do assombrosamente terrível ao assombrosamente belo, tudo é real, tragicamente real e repleto de imagens que nos convocam. Assim, tanto os mestres de capoeira quanto a literatura assumem um pacto: comprometem-se mutuamente com a dimensão da vida para que nos tornemos mestres.

Da mesma maneira, a criança quando brinca livremente faz o seu labor infantil, põe em potência esse poder demiúrgico de instaurar um cosmos, como aponta Gandhy Piorski (2016, p. 25): “A imaginação é a verdade da criança, o corpo semântico, a camada predileta, a fonte primordial de seus recursos de expressão. É um tempo e um espaço fantástico, conhecedor de 
origens". O que ele diz da criança aplica-se a todas as pessoas que conseguem acessar a potência da imaginação. Imaginar que nossos professores se tornem sensíveis ao poder da imaginação presente nas crianças, libertando-as para que possam criar novos caminhos que não somente aqueles previstos pelos professores, talvez seja uma das esperanças deste texto que aponta na direção de que professores se tornem mestres.

Sinto-me, ao fim, acompanhada o tempo todo neste texto pelo mensageiro, Hermes, aquele que permite fazer as trocas entre as diferentes camadas do real e do imaginário. $O$ trânsito entre o real e o imaginário que eu quis demonstrar, ainda que com lacunas, ao longo deste texto. Dou notícias de uma certa construção que em mim se fez e ainda se faz. Há espaços para vibrações. Deixo vazios para que o leitor possa completar, preencher ou, quem sabe, por causa da falta, esse leitor possa continuar a busca. Na falta do dito, fica a cumplicidade e o amor à busca pelo conhecimento, à sabedoria. Numa palavra: filosofia. Parece que foi a este caminho que me conduziu essa ciência: para a antropologia do imaginário. Sinto-me honrada por poder escrever, sentir e pensar em companhia destes mensageiros, mestres de todos os tempos!

A conversar com uma amiga que é ceramista, dizíamos dessa qualidade de pessoas que são os insatisfeitos e que, por isso mesmo, tornam-se artistas. Complementarmente, afirma-se neste texto que a maestria se constrói por esse caminho de busca. Todo mestre é um insatisfeito, um buscador. Que as potências da roda de capoeira, do brincar e da literatura, modulações de uma educação de sensibilidade, cujas raízes se sustentam nos saberes ancestrais - também chamados de mitológicos -, possam ser um trajeto para quem se faz professor. Recordo a epígrafe desta seção e fica a esperança de que e para além de professor, cada pessoa possa tornar-se uma referência, um mestre iniciador das novas gerações na cultura, através da cultura e valendo-se das artes, nas várias culturas. Com razão e sensibilidade. Evoé!

\section{Referências}

ALMEIDA, Rogério de. Educação Contemporânea: a sociedade autolimpante, o sujeito obsoleto e a aposta na escolha. Educação: Teoria e Prática. Rio Claro-SP, v. 20, n. 34, jan.-jun. 2010, p.47-64. Disponível em http://www.periodicos.rc.biblioteca.unesp.br/index.php/educacao/article/view/2850 Acesso em 09/07/2020.

ANDRADE, Mario de. Contos de Belazarte. Belo Horizonte: Villa Rica, 1992. 
ANDRADE, Mario de. Contos novos. 17.ed. Belo Horizonte: Editora Itatiaia, 1999.

ARAÚJO, Alberto Filipe; ALMEIDA, Rogério de. Fundamentos metodológicos do imaginário: mitocrítica e mitanálise. Téssera. Uberlândia, MG. v.1. n.1. p.18-42. jul./dez. 2018. Disponível em http://www.seer.ufu.br/index.php/ tessera/article/view/42944 Acesso em 08/07/2020.A

BACH, Richard. A história de Fernão Capelo Gaivota. Rio de Janeiro: Editorial Nórdica, 1977.

BARTHES, Roland. Aula. São Paulo: Cultrix, 2013.

BRÉSIO, Sabrina da Paixão. Nas trilhas do herói. histórias em quadrinhos \& itinerários de formação. Dissertação de Mestrado. Faculdade de Educação da USP. São Paulo, 2016. Disponível em https://www.teses.usp.br/teses/disponiveis/48/48134/tde-29112016-143725/pt-br.php Acesso em 08/07/2020.

DUBORGEL, Bruno. Imaginário e pedagogia. Lisboa: Instituto Piaget, 1992.

DURAND, Gilbert. A imaginação simbólica. São Paulo: Cultrix, Editora da Universidade de São Paulo, 1988.

DURAND, Gilbert. As estruturas antropológicas do imaginário: introdução à arquetipologia geral. Lisboa: Editorial Presença, 1989.

FERREIRA-SANTOS, Marcos. Crepusculário: conferências sobre mitohermenêutica \& educação em Euskadi. São Paulo: Zouk, 2004.

FERREIRA-SANTOS, Marcos. Novas mentalidades e atitudes: diálogos com a velha educação de sensibilidade. Conferência no $X V$ encontro estadual da APASE. São Paulo: 2001. Disponível em: <http://www.nossosaopaulo.com.br/ Reg_SP/Educacao/M_EducSensib.htm >. Acesso em: 18 abr. 2004.

FERREIRA-SANTOS, Marcos. Espaços crepusculares: poesia, mitohermenêutica e educação de sensibilidade. Revista @mbienteeducação (São Paulo), v.1, n. 1, jan/julho 2008. Disponível em: <http://www.cidadesp.edu.br/old/revista_educacao/pdf/volume_1/ art10marcos.pdf >. Acesso em: 14 jun. 2011.

FERREIRA-SANTOS, Marcos; ALMEIDA, Rogério de. Antropolíticas da educação. (Orgs.) São Paulo: Képos, 2011.

FERREIRA-SANTOS, Marcos; ALMEIDA, Rogério de. Aproximações ao imaginário: bússola de investigação poética. São Paulo: Képos, 2012. 
FÉTIZON, Beatriz. Sombra e luz: o tempo habitado. São Paulo: Zouk, 2002.

FRIEDMANN, Adriana. O olhar antropológico por dentro da infância: adentrando nas casinhas das crianças. In: MEIRELLES, Renata (Org.). Território do brincar: diálogos com escolas. São Paulo: Instituto Alana, 2014. p. 37-45.

GIBRAN, Khalil Gibran. Uma lágrima e um sorriso. Rio de Janeiro: ACIG, 1977.

GIBRAN, Khalil Gibran. O profeta. Rio de Janeiro: ACIG, 1980.

GIBRAN, Khalil Gibran. Areia e espuma. Rio de Janeiro: ACIG, 1981.

GUSDORF, Georges. Professores para quê? Para uma pedagogia da pedagogia. 3.ed. São Paulo: Martins Fontes, 2003.

IPHAN, Dossiê. Roda de Capoeira e Ofício dos Mestres de Capoeira. Instituto do Patrimônio Histórico e Artístico Nacional. Ministério da Cultura e do Desporto, Brasília, 2008.

LARROSA, Jorge. Tremores: escritos sobre a experiência. Belo Horizonte: Autêntica, 2014.

LEMOS, Liliane Benevenuto. Fiando o canto: sabedoria e imaginação simbólica na tessitura da tecelã. Dissertação de Mestrado. Faculdade de Educação da USP. São Paulo, 2020.

MAFFESOLI, Michel. O conhecimento Comum: compêndio de sociologia compreensiva. São Paulo: Brasiliense, 1985.

MAFFESOLI, Michel. No fundo das aparências. Rio de Janeiro: Vozes, 1996.

MAFFESOLI, Michel. Elogio da razão sensível. 2.ed. Rio de Janeiro: Vozes, 2001.

MAFFESOLI, Michel. O instante eterno: o retorno do trágico nas sociedades pós-modernas. São Paulo: Zouk, 2003.

MAFFESOLI, Michel. A sombra de Dioniso. 2.ed. São Paulo: Zouk, 2005.

NIETZSCHE, Friedrich. Humano, demasiado humano. São Paulo: Companhia das Letras, 2005.

NIETZSCHE, Friedrich. A origem da tragédia. São Paulo: Centauro, 2008.

NIETZSCHE, Friedrich. Ecce homo. São Paulo: Companhia das Letras, 2008a. 
NIETZSCHE, Friedrich. Assim falou Zaratustra. 18.ed. Rio de Janeiro: Civilização Brasileira, 2010.

NUMA ESCOLA DE HAVANA (Título original: Conducta). Direção: Ernesto Daranas Serrano. Cuba: Esfera Cultural. Cinemascope, 2014. Disponível em: https://www.youtube.com/watch?v=Qd0t3i-AcEs. Acesso em: 13/09/2016.

PAIVA, Ilnete Porpino de. A capoeira e os mestres. Tese de doutorado. UFRN, 2007.

PIORSKI, Gandhy. Brinquedos do chão: a natureza, o imaginário e o brincar. São Paulo: Peirópolis, 2016.

RILKE, Rainer Maria. Cartas a um jovem poeta. São Paulo: Globo, 1995.

RUBIRA, Fabiana de Pontes. Contar e ouvir estórias: um diálogo de coração para coração acordando imagens. Dissertação de Mestrado. Faculdade de Educação da USP. São Paulo, 2006. Disponível em https://www.teses.usp. br/teses/disponiveis/48/48134/tde-04042014-133433/pt-br.php Acesso em 08/07/2020.

RUBIRA, Fabiana de Pontes. Dançando com o Minotauro nas noites: narração de estórias e formação humana. Tese de Doutorado. Faculdade de Educação da USP. São Paulo, 2015. Disponível em https://www.teses.usp.br/teses/disponiveis/48/48134/tde-25052015-111218/pt-br.php Acesso em 08/07/2020.

SATO, Michèle (coord.). Os condenados da pandemia. Cuiabá: GPEA, UFMT \& Editora Sustentável, 2020. Disponível em https://editorasustentavel.com.br/ os-condenados-da-pandemia/ Acesso em 19/06/2020.

SAURA, Soraia Chung. Planeta de boieiros: culturas populares e educação de sensibilidade no imaginário do bumba-meu-boi. Tese de Doutorado. Faculdade de Educação da USP. São Paulo, 2008. Disponível em https://www.teses. usp.br/teses/disponiveis/48/48134/tde-12032009-131837/pt-br.php Acesso em 08/07/2020.

STEINER, George. Lições dos mestres. Rio de Janeiro: Record, 2005.

TEIXEIRA, Maria Cecília Sanchez \& ARAÚJO, Alberto Filipe Gilbert Durand: imaginário e educação. Niterói: Intertexto, 2011.

TODOROV, Tzvetan. A Literatura em Perigo. RJ: Difel, 2014.

WILLMS, Elni Elisa. Nas tramas minúsculas do cotidiano de dois assentados: do ser estigmatizado ao criar-se Pessoa - uma tessitura possível pela poesia. 
In: COSTA, Wilse Arena da (Org.) Estigma e diferenças na educação: a necessidade de uma educação inclusiva. Cuiabá-EdUFMT, 2007. pp. 99-125.

WILLMS, Elni Elisa. A arte trágica como afirmação da existência: entremesclando Nietzsche e Rosa. In: Religare. v.8 n.2. Outubro 2011. João Pessoa: UFPB. 164-180. Disponível em: <http://www.periodicos.ufpb.br/index.php/ religare/article/view/12499>. Acesso em 22 jun. 2019.

WILLMS, Elni Elisa. Escrevivendo: uma fenomenologia rosiana do brincar. Tese de Doutorado. Faculdade de Educação da Universidade de São Paulo; orientação Marcos Ferreira-Santos. São Paulo: 2013. 350 p. Disponível em: <http:// www.teses.usp.br/teses/disponiveis/48/48134/tde-02122013-123139/pt-br. php>. Acesso em 22 jun. 2019.

WILLMS, Elni Elisa. Ave, escrita! In: Religare. v.10 n.2. Setembro 2013b. João Pessoa: UFPB. 188-192. Disponível em: <http://www.periodicos.ufpb.br/ ojs2/index.php/religare/article/view/17483>. Acesso em 22 jun. 2019.

WILLMS, Elni Elisa. Miguilim: a criança sofre: contribuições da educação de sensibilidade.Revista @mbienteeducação. Universidade Cidade de São Paulo Vol. 8. no 2 jul/dez, 2015 - 214-24. Disponível em: <http://arquivos.cruzeirodosuleducacional.edu.br/principal/old/revista_educacao/pdf/volume_2_15/ educacao_02_2015_214-224\%202.pdf>. Acesso em 22 jun. 2019.

WILLMS, Elni Elisa e GOMES, Fábio José Cardias. Educação de sensibilidade crepuscular: escrevivendo o corpo na capoeira angola. Polifonia, Cuiabá, MT, v. 21, n. 30, p. 209-227, jul-dez., 2014. Disponível em: <http://periodicoscientificos.ufmt.br/ojs/index.php/polifonia/article/view/2187>. Acesso em 22 jun. 2019.

Data de recebimento: 12.07.2019

Data de aceite: 07.07.2020 